\title{
Spectral and Thermal Studies of Some Binuclear Dimeric Mo-O-Mo Bridged Oxomolybdenum(V) Complexes with Bis(carboxamides) Derived from 4,4'-Diaminobiphenyl, 1,4-diaminobenzene with Anhydrides
}

\author{
D. KANAGAVEL ${ }^{*}$ and M. MARIA ALBERT DENISON
}

Department of Chemistry, Kamaraj College, Tuticorin-628 003, Tamilnadu, India devakanagavel12@gmail.com

Received 23 October 2013 / Revised 2 December 2013 / Accepted 2 January 2014

\begin{abstract}
A study of doubly bidentate ligands like 4,4'-bis-(phthalamidyl)biphenyl $\mathrm{Bd}(\mathrm{PAH})_{2}$, 4,4'-bis-(Succinamidyl)biphenyl $\mathrm{Bd}(\mathrm{SAH})_{2}$, 1,4-bis-(phthalamidyl)monophenyl $\mathrm{PPD}(\mathrm{PAH})_{2}$ and 1,4-bis-(succinamidyl)monophenyl $\operatorname{PPD}(\mathrm{SAH})_{2}$ with oxomolybdenum(V) is described. The complexes were prepared by reaction with the precursor $(\mathrm{PyH})_{2}\left[\mathrm{MoOCl}_{5}\right]$. The coordination behavior of the complexes have been determined with the help of elemental composition, infrared and electronic spectroscopy, cyclicvoltammetric and thermal studies.
\end{abstract}

Keywords: Biscarboxyamides, 4,4'-Diaminobiphenyl, 1,4- Diaminobenzene

\section{Introduction}

The oxomolybdenum(V) complexes is dominated by both terminal oxo and bridged Oxo binuclear species. Infact, the chemistry and structure of binuclear bridged molybdenum(V) complexes has been much interest, because redox centers of molybdenum containing enzymes. In general molybdenum is a necessary cofactor for a number of redox enzymes ${ }^{1-4}$. The ligands containing carboxyamide chain having $\mathrm{O}_{4}$ donor atoms and their complexes have pharmacological activities ${ }^{5-8}$. A number of reports on binucleating carboxyamide ligands with first row transition metals are available ${ }^{9-12}$, no study on the oxomolybdenum(V) complexes of such ligands has been reported. In this paper, we report the synthesis and spectral properties of oxomolybdenum(V) complexes of bis-(carboxyamide) ligands derived from 4,4' - diaminodiphenyl and 1,4-diaminobenzene reacted with Phthalic and Succinic anhydrides. The Structures of the ligands is depicted in the Figure 1.

\section{Experimental}

All chemicals were of analytical grade and were used without further purification. $(\mathrm{PyH})_{2}$ $\left[\mathrm{MoOCl}_{5}\right]$ was prepared by the literature method ${ }^{13}$. The bis-(Carboxyamides) were synthesized by substantially modifying a published method ${ }^{11}$. All the Complexes were prepared in nitrogen atmosphere. 


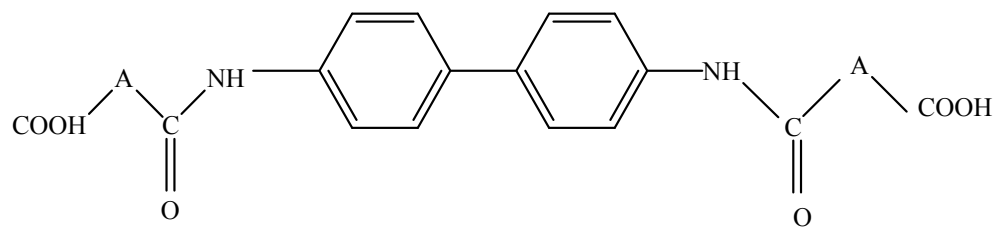

I - The structure of ligand (I) : $\mathrm{Bd}(\mathrm{PAH})_{2}, \mathrm{~A}=\mathrm{C}_{6} \mathrm{H}_{4} ; \mathrm{Bd}(\mathrm{SAH})_{2}, \mathrm{~A}=\mathrm{C}_{2} \mathrm{H}_{4}$<smiles>O=C(O)CC(=O)Nc1ccc(NC(=O)CC(=O)O)cc1</smiles>

II - The structure of ligand (II) : $\mathrm{PPD}(\mathrm{PAH})_{2}, \mathrm{~A}=\mathrm{C}_{6} \mathrm{H}_{4} ; \mathrm{PPD}(\mathrm{SAH})_{2}, \mathrm{~A}=\mathrm{C}_{2} \mathrm{H}_{4}$

\section{Synthesis of ligands}

Figure 1. Structure of the ligands

A solution of the appropriate diamines like 4,4'-diaminobiphenyl (Bd) or 1,4diaminobenzene (PPD) $(0.01 \mathrm{~mol})$ in absolute ethanol $\left(30 \mathrm{~cm}^{3}\right)$ was refluxed with the respective anhydrides like Phthalic $(\mathrm{PAH})$ or Succinic anhydride $(\mathrm{SAH})(0.02 \mathrm{~mol})$ in ethanol $\left(30 \mathrm{~cm}^{3}\right)$ for 2 to $4 \mathrm{~h}$. On cooling the corresponding carboxyamides precipitated out. The product was filtered, washed twice with ether and dried ${ }^{14}$.

\section{Synthesis of complexes}

About $0.48 \mathrm{~g}$ of $\mathrm{Bd}(\mathrm{PAH})_{2}$ was dissolved in $25 \mathrm{~mL}$ of absolute ethanol. To this $0.45 \mathrm{~g}$ of $(\mathrm{PyH})_{2}\left[\mathrm{MoOCl}_{5}\right]$ in $25 \mathrm{~mL}$ of absolute ethanol was added. The reaction mixture was heated to reflux for about an hour. The solid, that separated out was filtered, washed with ethanol, ether and dried under vacuum. A similar procedure was followed for the synthesis using the ligands $\mathrm{Bd}(\mathrm{SAH})_{2}, \mathrm{PPD}(\mathrm{PAH})_{2}$ and $\mathrm{PPD}(\mathrm{SAH})_{2}$.

\section{Measurements}

Molybdenum content was determined by a standard procedure ${ }^{15}$. The elemental analysis was carried out on a Heraeus model C,H,N - rapid analyser. The infrared spectra were recorded in $\mathrm{KBr}$ pellets on a JASCO IR-700 model spectrophotometer. The electronic spectra were recorded in DMF on a JASCO UVIDEC - 650 double beam spectrophotometer. Thermal Analysis were done on a Mettler TA 3000 micro processor with TG 50 Thermobalance and STA 1500 PL Thermal Sciences, heating at the rate of $20 \% \mathrm{~min}$. The cyclic voltammetric studies were performed on a BAS $-100 \mathrm{~A}$ or a BAS CV -27 electrochemical analyzer, using a glassy carbon working electrode (area $0.07 \mathrm{~cm}^{2}$ ), a platinum wire auxiliary electrode and a $\mathrm{Ag} / \mathrm{AgCl}$ reference electrode. Tetramethylammonium perchlorate $(0.1 \mathrm{M})$ was used as the supporting electrolyte with concentration of molybdenum compounds in millimolar range. The complexes were dissolved in purified and deaerated DMF. The experiments were carried out under an atmosphere of purified nitrogen.

\section{Results and Discussion}

The oxomolybdenum(V) Complexes were prepared by reacting the precursor $(\mathrm{PyH})_{2}$ $\left[\mathrm{MoOCl}_{5}\right]$ with the binucleating bis-(Carboxyamide) ligands. The analytical data correlates well with the calculated values assuming a metal: ligand ratio $1: 1$ indicating this to be the stoichiometry. 


\section{Analytical data of the complexes}

The analytical data for the binuclear carboxyamide ligands with oxomolybdenum(V) are given in Table 1. The experimental data correlates well with the calculated values assuming a metal: ligand ratio 1:1 indicating this to be the stoichiometry.

Table 1. Analytical data of the $\mathrm{Mo}(\mathrm{V})$ - oxo complexes

\begin{tabular}{cccccc}
\hline \multirow{2}{*}{ Complex } & \multirow{2}{*}{ Molecular Formula } & \multicolumn{4}{c}{ Found (calcd) \% } \\
\cline { 3 - 6 } & & $\mathrm{C}$ & $\mathrm{H}$ & $\mathrm{N}$ & $\mathrm{Mo}$ \\
\hline $\mathrm{Mo}-\mathrm{Bd}(\mathrm{PAH})_{2}$ & $\mathrm{Mo}_{4} \mathrm{O}_{6}\left(\mathrm{C}_{12} \mathrm{H}_{72} \mathrm{~N}_{8} \mathrm{O}_{24}\right)$ & $56.02(56.19)$ & $3.20(3.01)$ & $4.44(4.68)$ & $16.20(16.05)$ \\
Mo-Bd(SAH $)_{2}$ & $\mathrm{Mo}_{4} \mathrm{O}_{6}\left(\mathrm{C}_{80} \mathrm{H}_{72} \mathrm{~N}_{8} \mathrm{O}_{24}\right)$ & $47.99(48.81)$ & $3.46(3.59)$ & $5.49(5.57)$ & $19.08(19.12)$ \\
Mo-PPD(PAH $)_{2}$ & $\mathrm{Mo}_{4} \mathrm{O}_{6}\left(\mathrm{C}_{88} \mathrm{H}_{56} \mathrm{~N}_{8} \mathrm{O}_{24}\right)$ & $50.75(50.57)$ & $2.70(2.68)$ & $5.27(5.36)$ & $18.39(18.39)$ \\
Mo-PPD(SAH $)_{2}$. & $\mathrm{Mo}_{4} \mathrm{O}_{6}\left(\mathrm{C}_{56} \mathrm{H}_{56} \mathrm{~N}_{8} \mathrm{O}_{24}\right)$ & $39.38(39.44)$ & $3.17(3.29)$ & $6.48(6.57)$ & $22.40(22.53)$ \\
\hline
\end{tabular}

\section{Infrared spectra}

The infrared spectral data of the $\mathrm{Mo}(\mathrm{V})$ complexes from binucleating carboxyamide derivative shown in Table 2, a wide range of absorptions due to the $\mathrm{vMo}=\mathrm{O}$ stretching, (O-Mo-O) stretching frequencies and also the amide carbonyl, acid carbonyl and vNH stretching frequency of the amide group. In the present system, when compared to the spectral data of ligands, there is no appreciable change in $\mathrm{vNH}$ amide stretching frequency. The peaks are merged $\mathrm{vOH}$ stretching frequency of water (whose presence is inferred from the thermograms) and forms a broad band around ca. $3430 \mathrm{~cm}^{-1}$. The amide II absorption due to vNH bending of the secondary amide occurs at $1500-1600 \mathrm{~cm}^{-1}$. This band is not affected by complexation with the metal. The amide carbonyl group frequency appears around $1650-1600 \mathrm{~cm}^{-1}$ in the ligands. In the case of complexes, this absorption shifted to lower values by nearly $10-30 \mathrm{~cm}^{-1}$. This shift indicates the binding of the amide carbonyl group to metal on complexation. The acid carbonyl which appears around 1706-1715 $\mathrm{cm}^{-1}$ in the ligands, gets shifted to higher values by $10-15 \mathrm{~cm}^{-1}$ upon complexation, implying the involvement of acid carbonyl in binding to the metal. The infrared spectra of all $\mathrm{Mo}(\mathrm{V})$ complexes exhibit a strong band at ca. $970 \mathrm{~cm}^{-1}$, indicating the $\mathrm{Mo}_{2} \mathrm{O}_{3}{ }^{4+}$ core and is assigned to the molybdenum-terminal oxygen vibration $(\mathrm{vMo}=\mathrm{O})$. All Complexes exhibit medium intensity absorptions at ca.750-721 $\mathrm{cm}^{-1}$ and 451-424 $\mathrm{cm}^{-1}$, which are attributed to the antisymmetric and symmetric vibrations of Mo-O-Mo bridge ${ }^{16-18}$. The infrared data point to the ligands binding through the acid carbonyl and the amide carbonyl group to the metal ion in the complexes. All complexes show only one band in the region $970 \mathrm{~cm}^{-1}$ in presence of $\mathrm{Mo}_{2} \mathrm{O}_{3}{ }^{4+}$ core and also a medium intense absorption at 750 and $451 \mathrm{~cm}^{-1}$ indicating the presence of Mo-OMo bridge. The other characteristic absorption in the ligands do not undergo any distinct shift upon complexation.

Table 2. IR Spectral data $\left(\mathrm{in}^{-1}\right)$ and $\mathrm{CV}$ data of the $\mathrm{Mo}(\mathrm{V})$ - oxo complexes

\begin{tabular}{cccccc}
\hline Complex & $\begin{array}{c}\text { Amide I C=O } \\
\text { Amide II } \\
\text { N-H bend })\end{array}$ & $\begin{array}{c}\text { Acid } \\
\mathrm{C}=\mathrm{O}\end{array}$ & Mo $=\mathrm{O}$ & Epc $(\mathrm{V})$ & Epa $(\mathrm{V})$ \\
\hline Mo-Bd(PAH) & 1620,1508 & 1720 & 970 & $-0.76-0.30$ & $-0.39+0.34$ \\
Mo-Bd(SAH) $)_{2}$ & 1624,1587 & 1715 & 969 & $-0.78-0.38(\mathrm{Sh})$ & $+0.39(\mathrm{Sh})$ \\
$\mathrm{Mo-PPD}(\mathrm{PAH})_{2}$ & 1623,1560 & 1725 & 969 & $-0.78-0.36(\mathrm{Sh})$ & $-0.38+0.40(\mathrm{Sh})$ \\
$\mathrm{Mo-PPD}(\mathrm{SAH})_{2 .}$ & 1626,1561 & 1718 & 969 & $-0.77+0.36(\mathrm{Sh})$ & $-0.38+0.39(\mathrm{Sh})$ \\
\hline
\end{tabular}




\section{UV-Visible spectra}

The spectra of oxomolybdenum(V) complexes exhibit a shoulder at ca.19,600-19,800 $\mathrm{cm}^{-1}$. Which has been attributed to a transition involving the Mo-O-Mo bridge. This interpretation has been previously proposed to explain the origin of similar bands in the electronic spectra of analogous xanthate and dithiocarbamate dimmers ${ }^{16-21}$. The electronic spectrum shows a shoulder in the region ca. 19,608-19,724 $\mathrm{cm}^{-1}$ due to the transition ${ }^{2} \mathrm{~B}_{2} \rightarrow{ }^{2} \mathrm{~B}_{1}\left(\mathrm{dxy} \rightarrow \mathrm{dx}_{2}-\mathrm{y}_{2}\right)$. The band appearing as a shoulder in the region around $21,740-23,256 \mathrm{~cm}^{-1}$ is due to the transition ${ }^{2} \mathrm{~B}_{2} \rightarrow{ }^{2} \mathrm{~A}_{1}\left(\mathrm{dxy} \rightarrow \mathrm{dz}_{2}\right)$. Other shoulders are possibly obscured by the intra ligand transitions. ${ }^{22}$

\section{Cyclic voltammetric study}

The data from the cyclic voltammograms for the complexes is given in the Table 2. In the present system, all the oxomolybdenum(V) complexes exhibit a reduction peak at -0.56 to $0.78 \mathrm{~V}$. The corresponding anodic wave is seen at -0.35 to $-0.38 \mathrm{~V}$ in the case of the $\mathrm{Bd}(\mathrm{PAH})_{2}, \mathrm{PPD}(\mathrm{PAH})_{2}$ and $\mathrm{PPD}(\mathrm{SAH})_{2}$ complexes. Such a wave is not present in the $\mathrm{Bd}(\mathrm{SAH})_{2}$ complexes. An anodic peak is present in the range +0.34 to $+0.40 \mathrm{~V}$ in the cyclic voltammograms of the complexes. When the scan rate increases from 0.050 to $0.500 \mathrm{Vs}^{-1}$, the height of the reduction as well as oxidation peak increases. Sayer et al., ${ }^{15}$ have studied the electrochemistry of molybdenum (VI) and (V) with 8 - quinolinol complexes in dimethylsuphoxide. They observed that the oxobridged dimeric $\mathrm{Mo}(\mathrm{V})$ complex shows three cathodic peaks and an anodic peak. They decided that the anodic peak produces the Mo(VI) complexes in an irreversible process. From the above data, the oxomolybdenum(V) complexes have a well-defined reduction peak in the range -0.56 to $-0.78 \mathrm{~V}$. It is inferred that the reduction is quasi reversible since the anodic wave is obscured. $\Delta \mathrm{Ep}$ is much larger than that theoretically predicted confirming the quasi-reversible nature of the reduction. The anodic peak found in the range $+0.40 \mathrm{~V}$ indicates a one electron oxidation to produce $\mathrm{Mo}(\mathrm{VI})$ and is a totally irreversible process.

\section{Thermal study}

Thermograms were recorded for the $\mathrm{Mo}(\mathrm{V})$ complexes with $\mathrm{Bd}(\mathrm{SAH})_{2}, \mathrm{Bd}(\mathrm{PAH})_{2}$ and $\operatorname{PPD}(\mathrm{SAH})_{2}$. All the complexes lose water or solvent molecule below $100{ }^{\circ} \mathrm{C}$. In addition all three complexes undergo decomposition in three stages. The first stage occurs around $200{ }^{\circ} \mathrm{C}$, the second stage around $300^{\circ}-350{ }^{\circ} \mathrm{C}$ and the third stage around $800^{\circ} \mathrm{C}$. All three stages appear to be exothermic as indicated by DTA curve for the $\mathrm{Mo}(\mathrm{V})-\mathrm{PPD}(\mathrm{SAH})_{2}$ complex. It has not been possible to identify the fractions volatilizing at different stages of the thermal loss. The thermograms of the $\mathrm{Mo}(\mathrm{V})-\mathrm{Bd}(\mathrm{PAH})_{2}$ and $\mathrm{Mo}(\mathrm{V})-\mathrm{Bd}(\mathrm{SAH})_{2}$ were subjected to a kinetic analysis using the method of Coats and Redfern ${ }^{23}$. A linear regression of the values of the terms with $n=0,1 / 2,2 / 3$ and $n=1$ against $1 / T$ was carried out ${ }^{24}$. The weight loss step from $290-410{ }^{0} \mathrm{C}$ in the thermogram of $\mathrm{Mo}(\mathrm{V})-\mathrm{Bd}(\mathrm{PAH})_{2}$ corresponds to a zero order decomposition as indicated by a fair correlation coefficient for the line involving $n=0$. For this step an energy of activation of $105.30 \mathrm{Jmol}^{-1}$ has been calculated. Similar analysis of the weight loss step starting at $600{ }^{\circ} \mathrm{C}$ shows this step also follows a zero order decomposition, for this step the energy of activation has a value of $94.72 \mathrm{Jmol}^{-1}$. In the case of $\mathrm{Mo}(\mathrm{V})-$ $\mathrm{Bd}(\mathrm{SAH})_{2}$, the weight loss step from $65-150{ }^{\circ} \mathrm{C}$ shows a first order decomposition as indicated by the large correlation coefficient for the line involving $n=1$. For this step an energy of activation of $35.93 \mathrm{Jmol}^{-1}$ has been calculated. Similar analysis of the weight loss steps between $270-400{ }^{\circ} \mathrm{C}$ and $830-890{ }^{\circ} \mathrm{C}$ follow a first order and zero order decay with an energy of activation of 103.75 and $341.92 \mathrm{Jmol}^{-1}$ respectively. 


\section{Conclusion}

Based on the results of elemental analysis, spectral, electrochemical and thermal studies data, it is inferred that the ligand molecule binds to the metal through the amide oxygen and the carboxyl oxygen atoms and bridges two molybdenum centers. The basic unit containing molybdenum appears to be the $\mathrm{Mo}_{2} \mathrm{O}_{3}$ unit with two terminal oxygen atoms and a bridging oxygen. This is a common observation with regards to complexes of oxomolybdenum(V). Thus the basic unit appears to contain four molybdenum atoms and four ligands, the proposed structure of the compound is depicted in Figure 2. The complexes are found to be soluble in DMF and DMSO, and negligibly soluble in other common solvents. This may be indicative of a polynuclear structure formed by the ligands acting as bridges between molybdenum centers. A part of the polymeric structure is depicted in Figure 3.

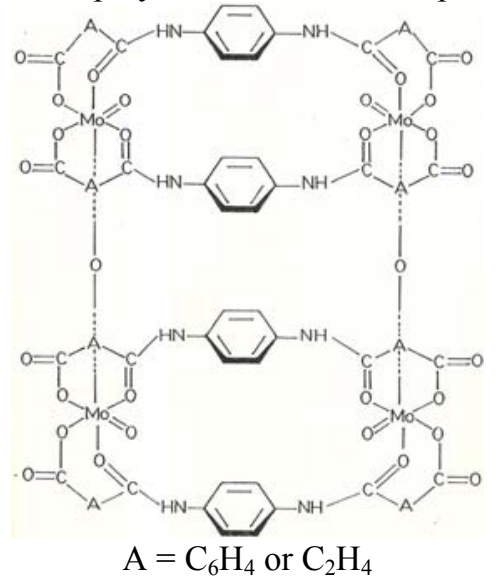

Figure 2. The structure of the Mo-Oxo complexes: $\mathrm{A}=\mathrm{C}_{6} \mathrm{H}_{4}$ or $\mathrm{C}_{2} \mathrm{H}_{4}$

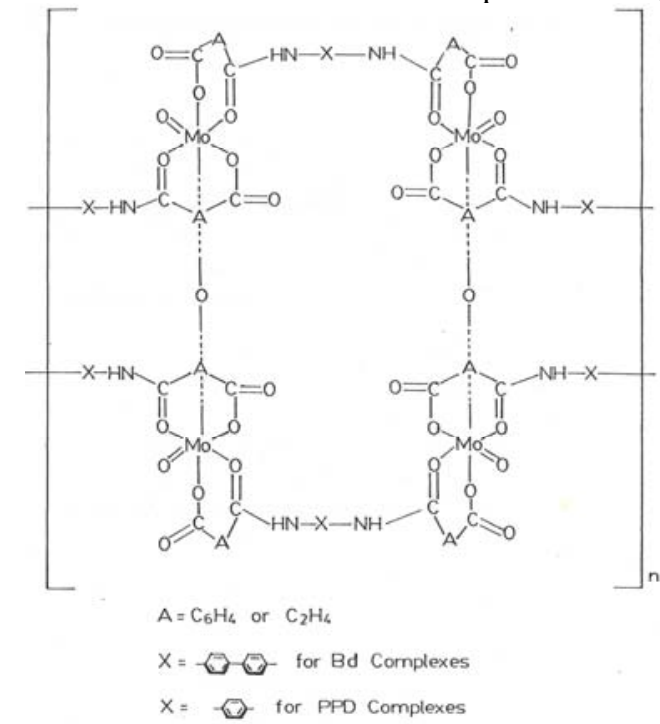

Figure 3. The structure of the Mo-Oxo complexes: $\mathrm{A}=\mathrm{C}_{6} \mathrm{H}_{4}$ or $\mathrm{C}_{2} \mathrm{H}_{4}: \mathrm{X}=$ complexes and for PPD complexes 


\section{References}

1. Bray R C, Enzymes, 1975, 12, 299.

2. Stiefel E I, Prog Inorg Chem., 1977, 22, 1.

3. Maurya R C, Shukla B and Pandey A, India J Chem., 2002, 41A, 554.

4. Harikumaran Nair M L and Devakiammal Thankamani, J Seb Chem Soc., 2011, 76(2), 221.

5. Williams D R, Chem Rev., 1972, 72(3), 203-213; DOI:10.1021/cr60277a001

6. Sigel H and Martin R B, Chem Rev., 1982, 82(4), 485-426, DOI:10.1021/cr00050a003

7. Raymond K N and Carano C J, Accts Chem Res., 1979, 12(5), 183-190; DOI:10.1021/ar50137a004

8. Jeyakumar K and Chand D K, J Chem Sci., 2009, 121(2), 111-123; DOI:10.1007/s12039-009-0013-Z

9. Sarojini T and Ramachandraiah A, Indian J Chem., 1990, 29A, 1174.

10. Ganesh K S and Krishnan C N, Synth React Inorg Met Org Chem., 1994, 24(10), 1798-1803; DOI:10.1080/00945719408003173

11. Sunilkumar Patil K, Vinayak Naik M and Nirmal Kumar Mallur B, Derpharma Chemica, 2012,4(5), 1812-1818.

12. Sanz R and Pedrosa M R, Curr Org Synth., 2009, 6, 239.

13. Sasaki Y, Taylor R S and Syker A G, J Chem Soc., Dalton Trans., 1975, 396-400.

14. Devakirubairajan Kanagavel and Coimbatore Krishnan N, Trans Met Chem., 1996, 21(6), 570-572; DOI:10.1007/BF00229715

15. Bassett J, Denney R C, Jaffery G H and Mendham J, "Vogel's Text book of Quantitative Inorganic Analysis”, Fourth Edition, English Language Book Society, London.1979, 160.

16. Pickett C, Kumar S, Vella P A and Zubieta J, Inorg Chem., 1982, 21(3), 908-916; DOI:10.1021/ic00133a012

17. Newton W D, Corbin J L, Bravard D C, Searles J E and Mcdonald J W, Inorg Chem., 1974, 13(5), 1100-1104; DOI:10.1021/ic50135a018

18. Harikumaran Nair M L and Nisha Kumari K R, Asian J Chem., 2007, 19, 4689-4696.

19. Cotton F A and Morehouse S M, Inorg Chem., 1965, 4(10), 1377-1381; DOI:10.1021/ic50032a001

20. Yamanouchi K and Yamada S, Inorg Chim Acta, 1974, 9, 83-86; DOI:10.1016/S0020-1693(00)89887-4

21. Dey K, Maiti R K and Bhar J K, Transition Met Chem., 1981, 6(6), 346-351; DOI:10.1007/BF00623654

22. Isbell A F and Sawyer D T, Inorg Chem., 1971, 10(11), 2449-2457;

DOI:10.1021/ic50105a018

23. Coats A W and Redfern J P, Nature, 1964, 201, 68-69; DOI:10.1038/201068a0

24. Sridevi N and Yusuff K K M, Indian J Chem., 2008, 47A, 836. 